\title{
Anthropometric studies on African athletes who participated in the 1st African University Games
}

\author{
BY J. D. WATSON AND D. Y. DAKO \\ Department of Nutrition and Food Science, University of Ghana, \\ PO Box 134, Legon, Ghana
}

(Received 19 July 1976 - Accepted 27 May 1977)

1. Height, weight, skinfold thicknesses and mid-arm circumference were measured in 540 males and 117 females aged 20-24 years who took part in the 1st African University Games, held at the University of Ghana, Legon. Body fat content, Quetelet's index (weight $\div$ height $\times 100$; Khosla \& Lowe $(1967)$ ) and mid-arm muscle circumference were derived from the measurements taken.

2. The physique or body-build of the subjects as assessed by Quetelet's index showed that both male and female subjects from the various countries were of medium body-build. The body fat content for males was between 10 and $12 \%$ with the exception of the Egyptians $(12.8 \%$ while that of females was between $23-24 \%$.

3. Body measurements of the subjects compared favourably with that of international standards (WHO, 1966) with the exception of the triceps skinfold thickness which was only approximately $60 \%$ of the standard value.

4. The low values for triceps skinfold thickness are probably due to differences in the distribution of subcutaneous fat at different sites in the body as found between caucasian and non-caucasian population groups. The results are discussed in relation to the findings of other workers on ethnic differences in skinfold thickness.

Measurements of height, weight and other body measurements have been carried out fairly extensively in many countries of the developed world. These studies have formed the basis on which anthropometric standards have come to be established for those countries. In the African continent there is a lack of sufficient information on the body measurements of African subjects which could be used for the setting up of suitable standards applicable to the local population groups. In fact Jellife (WHO, 1966) has stated that local standards are preferred to international standards in assessing the nutritional status of a community, although the international standard could serve as a means of comparing the information from surveys conducted at different times and places.

In order to set up anthropometric standards it is desirable to collect information from physically-fit, adequately-nourished persons. Many of the studies carried out on the body measurements of African subjects have been made on children and only a few on adult subjects; also those carried out have been on random samples from different population groups. We had therefore taken the opportunity of studying the body measurements of the male and female participants at the 1st African University Games, who we believe were in a physically-fit condition, and therefore served as ideal subjects for providing information for the compilation of standards of reference.

However, we were also interested in investigating reports of earlier workers such as Eksmyr \& Engsner (1971), Katzarski \& Ofosu-Amaah (1973) and Robson (1964) who found differences in the distribution of body fat between caucasian and non-caucasian populations. These earlier workers had found that in African subjects fat distribution, as given by skinfold thicknesses, tends to be greater in the subscapular than in the triceps region, whereas the reverse was true of caucasian populations. 


\section{EXPERIMENTAL}

\section{Subjects}

The subjects were the athletes who participated in the 1st African University Games held at the University of Ghana, Legon, in December 1974. The subjects were drawn from thirteen different countries within Africa and these countries are listed, together with the respective numbers of subjects examined, in Table 1. The mean ages of the male and female participants were between 20 and 24 years, with the exception of the Togolese females whose mean age was 19 years. The main sporting activities at the games together with the respective numbers of participants (in parentheses) were: male subjects: soccer (150), basket ball (97), athletics (88), volley ball (80), hand ball (30), swimming (21), lawn tennis (18), table tennis (16); female subjects: volley ball (36), basket ball (30), athletics (30), lawn tennis (8), table tennis (7), swimming (7).

With respect to the athletes, the number from any one country taking part in any one athletic event was not large and not all countries entered participants for the events available. The only exception was Ghana which contributed forty of a total of eighty-eight male athletes and fourteen of a total of thirty female athletes. Of the Ghanaian athletes not more than three persons took part in any one of the track and field events.

The measurements were taken at the Halls of Residence of the University of Ghana, where the subjects were residing during the period of the games.

\section{Methods}

All subjects were weighed, measured for height, skinfold thickness and arm circumference. Each subject's age, sex and nationality were recorded.

Weights were measured using a portable weighing machine (Salter No. 230; George Salter \& Co. Ltd, High Holborn, London WC1) with a zero adjustment. The accuracy of the machine was checked regularly at intervals against standard weights. The subjects were made to stand comfortably and steadily on the machine with minimum clothing (usually shorts and vests) and without shoes. No allowance was made for clothing worn by subjects. Height measurements were taken with the subject standing erect with no head tilt and without shoes or head gear, using a portable anthropometer (Harpenden; Holtain Ltd, Crosswell, Crymych, Dyfed, UK).

Arm circumference was measured using a nylon tape (Brevete S.C.D.C. no. 120; Stanley; Mabo, France) at a site half-way between the tip of the acromion and the olecranon process.

Skinfold thickness was measured at the biceps, triceps, subscapular and supra-iliac sites using a skinfold caliper (Holtain Ltd) which exerted a constant pressure of $10 \mathrm{kN} / \mathrm{m}^{2}$ over its entire operating range. All measurements were taken on the left side of the body according to WHO recommendations (Faulkner, 1960). The technique described by Durnin \& Rahaman (1967) was used in measuring each skinfold thickness, and also for deriving the body fat content ( $\%$ body-weight) from the total skinfold values.

Mid-arm muscle circumference was derived from the arm circumference and triceps skinfold thickness using the normogram developed by Gurney \& Jellife (1973).

The weight-height relationship has been expressed by the use of Quetelet's index (weight $(\mathrm{kg}) \div$ height $(\mathrm{m}) \times 100$; Khosla \& Lowe $(1967)$ ). The values obtained were used to assess the physique of the subjects in terms of their body-build. 


\section{RESULTS}

The values for the various measurements grouped according to sex, country and region within the African continent are presented in Tables 1 and 2 . The mean value with the standard deviation for each measurement are presented.

\section{Height patterns}

The mean heights for males from West Africa were $1.74 \mathrm{~m}$ compared with $1.79 \mathrm{~m}$ for North Africans and $1.74 \mathrm{~m}$ for Middle and East Africans. Among West Africans there was little variation in height, whereas of the North Africans, the Egyptians $1.81 \mathrm{~m}$ were taller than the Algerians and also taller than any other group. Of the Middle and East Africans those from the Congo and Zambia were taller than those from Gabon and Uganda. The Sudanese had heights similar to subjects from West Africa.

The mean heights of females from West Africa was $1.61 \mathrm{~m}$ and was similar to those from Egypt (North Africa) $1.62 \mathrm{~m}$. Among the females from West Africa, the Togolese were the shortest with a mean height of $1.59 \mathrm{~m}$.

\section{Weight patterns}

The mean weights for males from West Africa were $67.5 \mathrm{~kg}$ compared with $75.3 \mathrm{~kg}$ for North Africans and $67.0 \mathrm{~kg}$ for Middle and East Africans. There was little variation in the weight of subjects from West Africa with the exception of those from Ivory Coast whose mean weight was $70.0 \mathrm{~kg}$. Among the North Africans, the Egyptians were heavier than the Algerians $(77 \cdot 0 \mathrm{~kg} v .71 \cdot 1 \mathrm{~kg}$ ), while of those from Middle and East Africa, the Congolese and Zambians were the heaviest with mean weights of $72.0 \mathrm{~kg}$ and $67.7 \mathrm{~kg}$ respectively. The Sudanese had the lowest mean body-weight $(63.9 \mathrm{~kg})$.

The mean weights of females from West Africa were $55.7 \mathrm{~kg}$ compared to $59.4 \mathrm{~kg}$ for Egyptians. Among the West African females, the Togolese had the lowest mean bodyweight $(52.6 \mathrm{~kg})$ but this may partly be due to the fact that the mean age of the Togolese was 19 years compared to that of 22 years for the other groups.

\section{Skinfold thickness}

Biceps. There was little variation between the various groups; the mean values for males were between 3 and $4 \mathrm{~mm}$ and that for females was between 5 and $6 \mathrm{~mm}$.

Triceps. There was little variation among the groups; the mean values for males were between 4.5 and $5.5 \mathrm{~mm}$, with the exception of those from Egypt $(6.1 \mathrm{~mm})$ and those of females were approximately $10 \mathrm{~mm}$, with the exception of those from Liberia $(8.7 \mathrm{~mm})$ and Sierra Leone $(12.0 \mathrm{~mm})$.

Subscapular. There was little variation in the mean values for males which were between 7.8 and $8.8 \mathrm{~mm}$ or those for females which were between 9.0 and $10.5 \mathrm{~mm}$.

Supra-iliac. Mean values for males were between 6.0 and $7.0 \mathrm{~mm}$ with the exception of North Africans and Sudanese which had mean values of $9.8 \mathrm{~mm}$ and $8.3 \mathrm{~mm}$ respectively. Those of females were between 10 and $11 \mathrm{~mm}$ with the exception of Liberians $(13.9 \mathrm{~mm})$ and Egyptians $(13.0 \mathrm{~mm})$.

Total skinfold thickness. For males, values were between 22 and $24 \mathrm{~mm}$ with the exception of Egyptians $(28.7 \mathrm{~mm})$, Gabonese $(24.9 \mathrm{~mm})$ and Nigerians $(25.1 \mathrm{~mm})$; for females, values were between 35 and $38 \mathrm{~mm}$, with the exception of Egyptians $(38.9 \mathrm{~mm}$ ) and Ghanaians $(40.4 \mathrm{~mm})$.

Body fat. Values for male subjects were approximately $10-11 \%$ body-weight with the 
Table 1. Age (years), height $(\mathrm{m})$, weight $(\mathrm{kg})$, Quetelet's index (weight $\div$ height $\times 100$; Khosla \& Lowe (1967)) and body fat content (\% body-weight) of African athletes

(Mean values and standard deviations)

\begin{tabular}{|c|c|c|c|c|c|c|c|c|c|c|}
\hline \multirow[b]{2}{*}{ Country } & \multirow{2}{*}{$\begin{array}{l}\text { No. of } \\
\text { subjects }\end{array}$} & \multicolumn{2}{|c|}{$\overbrace{}^{\text {Age }}$} & \multicolumn{2}{|c|}{ Height } & \multicolumn{2}{|c|}{ Wt } & \multirow{2}{*}{$\begin{array}{l}\text { Quetelet's } \\
\text { index }\end{array}$} & \multicolumn{2}{|c|}{ Body fat } \\
\hline & & Mean & SD & Mean & SD & Mean & SD & & Mean & SD \\
\hline \multicolumn{11}{|c|}{ (a) Males } \\
\hline $\begin{array}{l}\text { Ghana } \\
\text { Nigeria } \\
\text { Sierra Leone } \\
\text { Liberia } \\
\text { Ivory Coast } \\
\text { Togo }\end{array}$ & $\begin{array}{r}120 \\
68 \\
25 \\
40 \\
68 \\
74\end{array}$ & $\begin{array}{l}23 \cdot 8 \\
23 \cdot 8 \\
22 \cdot 8 \\
21 \cdot 8 \\
22 \cdot 4 \\
22 \cdot 1\end{array}$ & $\begin{array}{l}2 \cdot 84 \\
3.08 \\
2 \cdot 50 \\
1.89 \\
1.69 \\
2.04\end{array}$ & $\begin{array}{l}1.74 \\
1.75 \\
1.73 \\
1.73 \\
1.74 \\
1.75\end{array}$ & $\begin{array}{l}0.063 \\
0.069 \\
0.068 \\
0.074 \\
0.062 \\
0.059\end{array}$ & $\begin{array}{l}66 \cdot 60 \\
68 \cdot 00 \\
65 \cdot 84 \\
65 \cdot 30 \\
70 \cdot 02 \\
67 \cdot 75\end{array}$ & $\begin{array}{l}7.04 \\
6.53 \\
5.91 \\
5.82 \\
6.89 \\
6.77\end{array}$ & $\begin{array}{l}0.22 \\
0.22 \\
0.22 \\
0.22 \\
0 \cdot 23 \\
0.22\end{array}$ & $\begin{array}{l}10.40 \\
11.24 \\
10.92 \\
10.86 \\
10.99 \\
11.01\end{array}$ & $\begin{array}{l}1 \cdot 90 \\
2 \cdot 01 \\
1 \cdot 73 \\
2 \cdot 11 \\
1 \cdot 85 \\
1 \cdot 83\end{array}$ \\
\hline West Africa & 395 & $23 \cdot 0$ & 2.57 & 1.74 & 0.066 & 67.50 & 6.80 & 0.22 & 10.85 & 1.95 \\
\hline $\begin{array}{l}\text { Egypt } \\
\text { Algeria }\end{array}$ & $\begin{array}{l}41 \\
17\end{array}$ & $\begin{array}{l}21 \cdot 5 \\
23 \cdot 4\end{array}$ & $\begin{array}{l}2.09 \\
2.71\end{array}$ & $\begin{array}{l}1.81 \\
1.76\end{array}$ & $\begin{array}{l}0.070 \\
0.054\end{array}$ & $\begin{array}{l}77 \cdot 00 \\
71 \cdot 12\end{array}$ & $\begin{array}{l}7.06 \\
5.05\end{array}$ & $\begin{array}{l}0.23 \\
0.23\end{array}$ & $\begin{array}{l}12 \cdot 80 \\
10 \cdot 67\end{array}$ & $\begin{array}{l}1.03 \\
1.72\end{array}$ \\
\hline North Africa & 58 & $22 \cdot 0$ & $2 \cdot 39$ & $1 \cdot 79$ & $0-069$ & $75 \cdot 28$ & 6.91 & $0 \cdot 23$ & $12 \cdot 18$ & $1 \cdot 3$ \\
\hline $\begin{array}{l}\text { Gabon } \\
\text { Congo } \\
\text { Uganda } \\
\text { Zambia }\end{array}$ & $\begin{array}{r}29 \\
16 \\
20 \\
7\end{array}$ & $\begin{array}{l}21 \cdot 4 \\
22 \cdot 3 \\
22 \cdot 8 \\
21 \cdot 3\end{array}$ & $\begin{array}{l}1 \cdot 13 \\
2 \cdot 00 \\
1 \cdot 94 \\
2 \cdot 14\end{array}$ & $\begin{array}{l}1.71 \\
1.79 \\
1 \cdot 72 \\
1.78\end{array}$ & $\begin{array}{l}0.050 \\
0.065 \\
0.061 \\
0.062\end{array}$ & & $\begin{array}{l}5 \cdot 45 \\
8 \cdot 82 \\
4 \cdot 29 \\
4 \cdot 35\end{array}$ & $\begin{array}{l}0.22 \\
0.22 \\
0.22 \\
0.21\end{array}$ & $\begin{array}{r}11.22 \\
9.74 \\
10.09 \\
10.64\end{array}$ & $\begin{array}{l}1.87 \\
2.03 \\
1.75 \\
1.09\end{array}$ \\
\hline $\begin{array}{l}\text { Middle and } \\
\text { East Africa }\end{array}$ & 72 & $21 \cdot 9$ & $1 \cdot 81$ & $1 \cdot 74$ & 0.067 & 66.99 & $6 \cdot 51$ & 0.22 & $10 \cdot 50$ & 1.89 \\
\hline Sudan & 15 & \multicolumn{6}{|c|}{ (b) Females } & 0.22 & $11 \cdot 03$ & $1 \cdot 38$ \\
\hline $\begin{array}{l}\text { Ghana } \\
\text { Nigeria } \\
\text { Togo } \\
\text { Sierra Leone } \\
\text { Liberia }\end{array}$ & $\begin{array}{r}44 \\
23 \\
16 \\
8 \\
8\end{array}$ & $\begin{array}{l}23 \cdot 3 \\
22 \cdot 3 \\
18 \cdot 9 \\
20 \cdot 1 \\
20 \cdot 3\end{array}$ & $\begin{array}{l}2.12 \\
2.78 \\
1.73 \\
1.81 \\
1.49\end{array}$ & $\begin{array}{l}1.61 \\
1.63 \\
1.59 \\
1.61 \\
1.64\end{array}$ & $\begin{array}{l}0.043 \\
0.048 \\
0.065 \\
0.082 \\
0.043\end{array}$ & $\begin{array}{l}55 \cdot 47 \\
58 \cdot 22 \\
52 \cdot 59 \\
55 \cdot 13 \\
56 \cdot 88\end{array}$ & $\begin{array}{l}4 \cdot 42 \\
8 \cdot 12 \\
6 \cdot 04 \\
3.87 \\
8 \cdot 44\end{array}$ & $\begin{array}{l}0.22 \\
0.22 \\
0.21 \\
0.21 \\
0.21\end{array}$ & $\begin{array}{l}23 \cdot 82 \\
23 \cdot 34 \\
22 \cdot 62 \\
23 \cdot 61 \\
23 \cdot 75\end{array}$ & $\begin{array}{l}3 \cdot 15 \\
4 \cdot 35 \\
3 \cdot 22 \\
2 \cdot 78 \\
2 \cdot 97\end{array}$ \\
\hline West Africa & 99 & 21.9 & $2 \cdot 58$ & $1 \cdot 61$ & 0.051 & $55 \cdot 73$ & $6 \cdot 17$ & $0 \cdot 21$ & $23 \cdot 49$ & $3 \cdot 40$ \\
\hline Egypt & 18 & $20 \cdot 1$ & $2 \cdot 17$ & 1.62 & $0 \cdot 049$ & $59 \cdot 44$ & $7 \cdot 33$ & 0.23 & 23.89 & 2.94 \\
\hline
\end{tabular}

exception of Egyptians (12.8\% body-weight); those for female subjects were approximately $22-24 \%$ body-weight.

Mid-arm circumference. Mean values for males were between 0.25 and $0.27 \mathrm{~m}$, with the exception of Egyptians $(0.28 \mathrm{~m})$; those for females were between 0.24 and $0.25 \mathrm{~m}$.

Mid-arm muscle circumference. Mean values for males were between 0.24 and $0.26 \mathrm{~m}$ with the exception of the Gabonese $(0.23 \mathrm{~m})$; those of females were between 0.20 and $0.21 \mathrm{~m}$.

\section{DISCUSSION}

Although the number of subjects examined was not large, this study has been an attempt to investigate the anthropometric characteristics of physically-fit, adequately-nourished subjects in the age-group 20-25 years, drawn from thirteen different African countries. The information obtained will serve as a contribution towards the compilation of standards of reference applicable to African population groups. It will also provide some indication whether there are any marked differences in the body dimensions of the racial groups within Africa.

Previous studies on the anthropometry of adult African subjects were confined mainly 


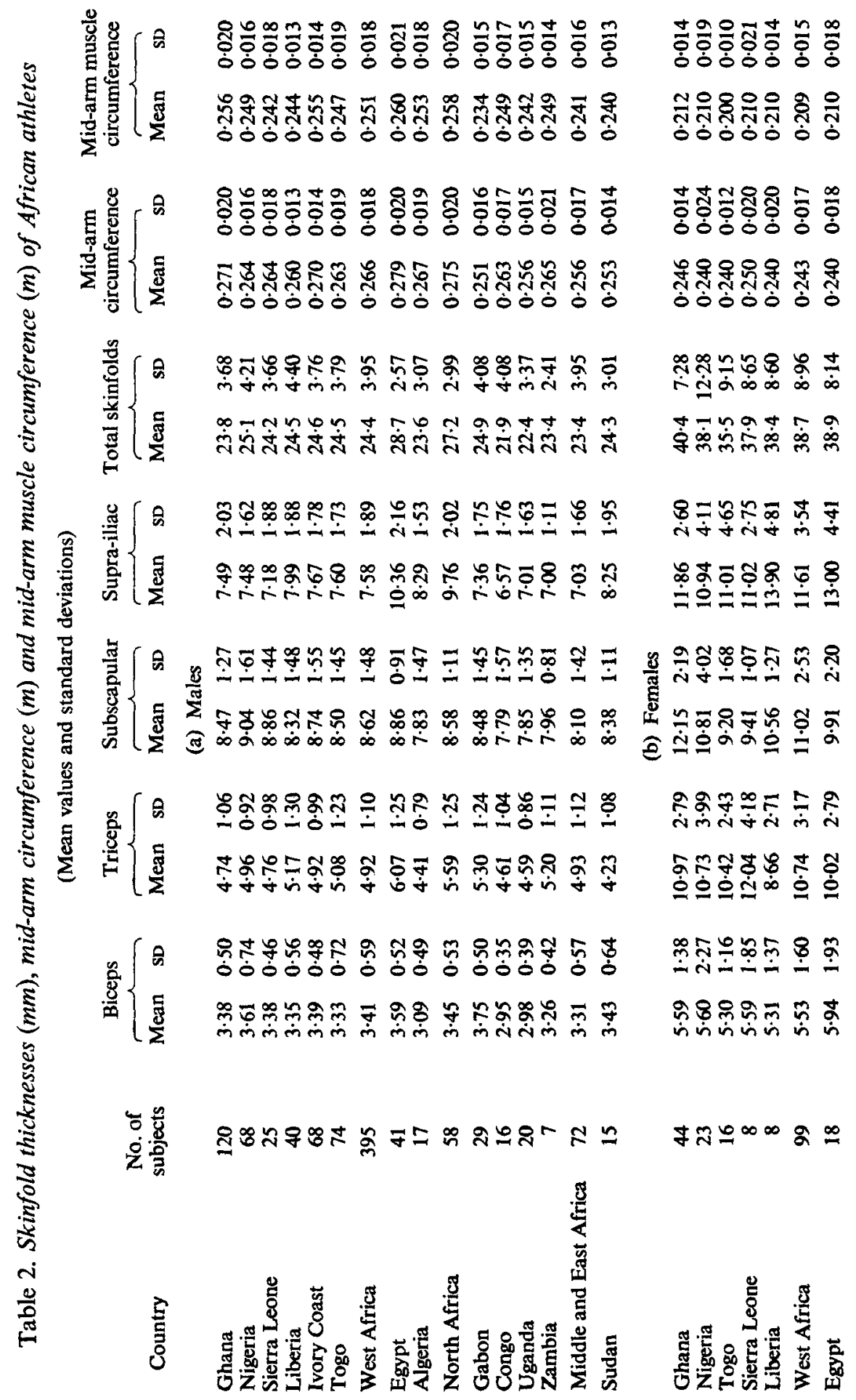




\section{Table 3. Comparison of information obtained in the present study with African athletes with WHO (1966) standards}

\section{Measurement}

Weight-for-height Mid-arm circumference Mid-arm muscle circumference Triceps skinfold thickness

\begin{tabular}{|c|c|}
\hline Males & Females \\
\hline $90-100$ & $90-100$ \\
\hline $85-90$ & $90-100$ \\
\hline $85-90$ & $90-95$ \\
\hline$<60$ & $60-75$ \\
\hline
\end{tabular}

to the measurements of height and weight only. Comparing our results with those of other workers for African subjects, as reported by Johnson (1970), indicates that our subjects were in most instances taller and heavier. One possible explanation for this is that our study was carried out on physically-fit, adequately-nourished subjects whereas the other studies, in most instances, were done on random samples selected from different population groups.

The physique or body-build of subjects may be assessed by means of the ponderal index (weight-height relationship as suggested by Durnin \& Rahaman (1967)). Robinson, Brucer \& Mass (1940) subdivided 'ponderal index' groups into light-weight $(\leqslant 0 \cdot 199)$ medium-weight $(0 \cdot 20-0 \cdot 249)$ and heavy-weight $(\geqslant 0 \cdot 25)$. Using their criterion the ponderal index, as given by Quetelet's index, would classify our male and female subjects as medium body-build. Using Durnin \& Rahaman (1967) criterion our male subjects would be classed as of thin body-build, while our female subjects would be of intermediate body-build. According to Parry (1969) a ponderal index of $0.20-0.26$ is regarded as being within the normal range $(0.20$ and 0.26 being regarded as the lower and upper limits respectively of normal). The ponderal index of all our subjects was within this range; most values being at the lower end of the range $(0 \cdot 22)$.

When we compare the mean values of some of the measurements with those of international standards (e.g. WHO, 1966) it is found that the body measurements of our subjects are within the upper ranges of the standard values, with the exception of the triceps skinfold thickness as shown in Table 3.

Although the triceps skinfold thickness was only approximately $60 \%$ of the WHO (1966) standard in the instance of both males and females, the total body fat content was very similar to that found in physically-fit caucasian populations of the same age-group, thereby suggesting differences in the fat distribution at specific sites. In fact Robson (1964) observed that comparing values he obtained for a group of healthy Tanganyikan African adolescents with those of Hammond (1955) for English adolescents, mean triceps thickness of the Africans was less than that of English adolescents of 'poor' nutritional status, but the subscapular skinfold thickness of the African subjects were comparable to those of English adolescents of 'good' nutritional status. Further Eksmyr \& Engsner (1971) in a 'pilot study' in Ethiopia found that the distribution of subcutaneous fat in Ethiopian school boys was different from that of British boys. The Ethiopians had relatively more surface fat located to their backs and relatively less located to the back of their upper arms. In this respect the Ethiopian boys were comparable to the boys examined by Robson (1964) in Tanganyika. More recently Watson \& Etta (1975) examined adult Nigerian male subjects, 18-29 years of age, and found that the subscapular thickness $(7 \cdot 1-9 \cdot 0 \mathrm{~mm})$ was greater than that of the triceps $(5 \cdot 1-5 \cdot 4 \mathrm{~mm})$.

There are similar reports of differences in the subcutaneous fat distribution in negroes in the United States (Piscopo, 1962; Malina, 1966) and in the Carribean (Robson, Bazin \& Sonderstrom, 1971). Also Albrink \& Meigs (1971) found that the mean triceps skinfold 
Table 4. Correlation coefficient ( $r$ for triceps and subscapular skinfold thicknesses $v$. total body fat content for African athletes

(Values in parentheses are ranges for countries within groupings)

\begin{tabular}{|c|c|c|c|c|}
\hline \multirow[b]{2}{*}{ Regional grouping } & \multirow[b]{2}{*}{ Sex } & \multirow{2}{*}{$\begin{array}{l}\text { No. of } \\
\text { subjects }\end{array}$} & \multicolumn{2}{|c|}{ Skinfold thickness } \\
\hline & & & Triceps & Subscapular \\
\hline West Africa & $\begin{array}{l}\hat{0} \\
\stackrel{0}{+}\end{array}$ & $\begin{array}{r}395 \\
99\end{array}$ & $\begin{array}{l}0.19(0.17-0.21) \\
0.54(0.51-0.60)\end{array}$ & $\begin{array}{l}0.54(0.52-0.57) \\
0.54(0.46-0.63)\end{array}$ \\
\hline North Africa & *o & $\begin{array}{l}58 \\
18\end{array}$ & $\begin{array}{l}0.27(0.25-0.29) \\
0.58\end{array}$ & $\begin{array}{l}0.56(0.52-0.59) \\
0.58\end{array}$ \\
\hline Middle and East Africa & $\hat{0}$ & 72 & $0.21(0 \cdot 18-0.24)$ & $0.53(0.50-0.55)$ \\
\hline Sudan & 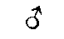 & 15 & $0 \cdot 23$ & 0.62 \\
\hline
\end{tabular}

thickness of lean Cape Verde Islanders, 20-29 years of age, was 5.5 mm compared to a mean value of $11.6 \mathrm{~mm}$ found in factory workers in USA.

In our study on subjects drawn from different countries in Africa, the ranges of mean values for triceps skinfold thickness $(\mathrm{mm})$ were 4.41-5.71 and those for subscapular skinfold thickness were 7.9-8.9 for males; the corresponding values (mm) for females were $8 \cdot 7-12 \cdot 0$ and $9 \cdot 2-10 \cdot 8$ respectively.

The findings in our male subjects are similar to those reported by other workers (Robson, 1964; Eksmyr \& Engsner, 1971; Katzarski \& Ofosu-Amaah, 1973; Watson \& Etta, 1975) and supports the view that there are differences in the distribution of subcutaneous fat as found in caucasian and non-caucasian populations. This hypothesis may be further supported by the fact that the total body fat content of our male subjects was in the range $9.8-12.0 \%$ body-weight and that of females was $22-24 \%$ body-weight; these values are very similar to the mean values found in caucasian populations. Macmillan, Reid, Shirling, \& Passmore (1965) found that in Edinburgh male medical students had approximately $10 \%$ body-weight as fat, the value for females was approximately $25 \%$ body-weight, while Durnin \& Rahaman (1967) found that the body fat content ( $\%$ body-weight) of young adult men and women was approximately 13 in males and 24 in females.

However, it should be borne in mind that in light of the differences in the distribution of subcutaneous fat at the four different sites between caucasian and non-caucasian populations one cannot be certain whether the Durnin \& Rahaman (1967) formula relating the sum of the four skinfolds to total body fat content is applicable to population groups where the distribution of body fat is different to that found in the caucasian.

The subscapular skinfold thickness variation closely paralled the variation in total skinfold thickness and that of total body fat content. This supports the concept put forward by Garn, Rosen \& McCann (1971) that the subscapular skinfold thickness most closely reflects the subcutaneous and total body fat content. Table 4 shows the correlation coefficients for triceps and subscapular skinfold thicknesses $v$. total body fat content. It can be observed that in the male subjects the subscapular skinfold thickness had a higher correlation with total body fat than triceps skinfold thickness; however, in the case of females the correlations were similar for both measurements.

The WHO (1966) adapted Hammond's (1955) values as standards of reference for the mean triceps skinfold thickness with age. The application of the WHO (1966) standards to non-caucasian populations and in particular to African subjects would place them in a category that would be much lower than their actual nutritional status. The fact that the amount of fat in the triceps region is less in the African than in caucasian races suggests 
that the use of reference standards based on information collected from one ethnic group should not be used for evaluating other ethnic groups.

Furthermore, it is also believed that other anthropometric measurements which are either derived values such as the rnid-arm muscle circumference based on triceps skinfold thickness, or information that has been pooled from several racial sources, may be invalid for use as standards for comparative purposes. Therefore, there is an urgent need for the setting up of locally-applicable standards and it is hoped that this study will provide useful information towards this end.

The authors wish to acknowledge the technical assistance given by Mr G. L. Mabey, chief technician in the Department of Nutrition and Food Science, University of Ghana and Mr G. Laniyan, 3rd year student in helping with the various measurements. They would also like to thank the organizers of the 1st African University Games in particular Dr J. E. A. Mills, Dr G. Benneh and Dr S. A. Banful, for granting permission to undertake this study, and to the participants for their patience and cooperation which enabled this study to be completed successfully.

\section{REFERENCES}

Albrink, M. J. \& Meigs, J. W. (1971). Am. J. clin. Nutr. 24, 344.

Durnin, J. V. G. A. \& Rahaman, M. M. (1967). Br. J. Nutr. 21, 681.

Eksmyr, R. S. \& Engsner, G. (1971). J. trop. Paediat. envir. Child Hlth 17, 110.

Faulkner, F. (1960). Modern Problems in Pediatrics, p. 439. Basle and New York: S. Karger.

Garn, S. M., Rosen, N. N. \& McCann, M. B. (1971). Am. J. clin. Nutr. 24, 1380.

Gurney, J. M. \& Jellife, D. B. (1973). Am. J. clin. Nutr. 26, 192.

Hammond, W. H. (1955), Br. J. prev. Soc. Med. 22, 65.

Johnson, T. O. (1970). Trop. Geogr. Med. 22, 65.

Katzarski, M. \& Ofosu-Amaah, S. (1973). Ghana med. J. 12, 287.

Khosia, T. \& Lowe, C. R. (1967). Br. J. prev. Soc. Med. 21, 122.

Macmillan, M. G., Reid, C. M., Shirling, D. \& Passmore, R. (1965). Lancet i, 728.

Malina, R. M. (1966). Human Biol. 38, 89.

Parry, E. H. O. (1969). E. Afr. med.J. 46, 246.

Piscopo, J. (1962). Res. Q. Am. Ass. Hith Phys. Educ. Rec. 33, 255.

Robinson, S. C., Brucer, M. \& Mass, J. (1940). J. Lab. clin. Med. $25,807$.

Robson, J. R. K. (1964). J. trop. med. Hyg. 67, 209.

Robson, J. R. K., Bazin, M. \& Sonderstrom, R. (1971). Am. J. clin. Nutr. 24, 864.

Watson, R. S. \& Etta, K. M. (1975). Br. J. Nutr. 33, 141.

WHO (1966). W.H.O. Monogr. ser. no. 53. 